DE89 013417

\title{
HEAVY ION FUSION ACCELERATOR RESEARCH (HIFAR) YEAR-END REPORT*
}

October 1, 1987 - March 31, 1988

\author{
Heavy Ion Fusion Staff \\ Accelerator and Fusion Research \\ Lawrence Berkeley Laboratory \\ University of Califomia \\ Berkeley, CA 94720
}

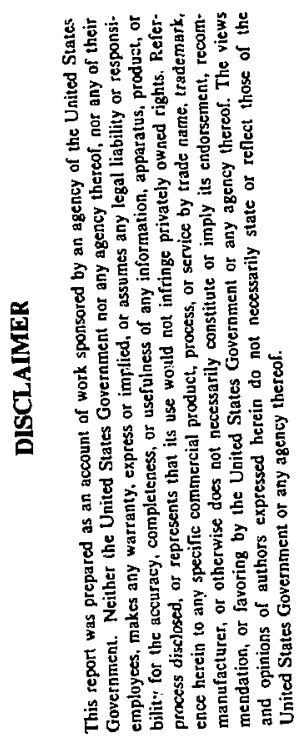

Attention: This document is provided for DOE "Official Use". Distribution to other interested parties is made with the understanding that no information or experimental results given herein will be quoted without first obtaining the authors' permission, or until such information or results have appeared in the open literature.

* This work was supported by the Office of Energy Research, Office of Basic Energy Sciences, U.S. Department of Energy under Contract No. DE-AC03-76SF00098. 


\section{TABLE OF CONTENTS}

Highlights

MBE-4 Acceleration

Modifications to MBE-4.

Carbon Arc Source Development

2-MV Injector

2-MV Injector Controi System

Progress Toward a Self-Consistent Physics Design for ILSE

Engineering Design for ILSE Beam-Combining

Packaging Study for the ILSE Magnetic-Focus Induction Cells

Field Characteristics of ILSE Magnetic-Quadrupole Lenses

Conceptual Design for the ILSE Electrostatic Focusing Accelerator

Support ard Alignment.

Transverse Mis-Alignments in a Driver.

Tolerance on Longitudinal Position of Quadrupoles

Publications and Internal Notes 18

H.I.F. Staff Roster 23

Distribution List .24 


\section{FOREWORD}

The basic objective of the Heavy Ion Fusion Accelerator Research (HIFAR) program is to assess the suitability of heavy ion accelerators as igniters for Inertial Confinement Fusion (ICF). A specific accelerator technology, the induction linac, has been studied at the Lawrence Berkeley Laboratory and has reached the point at which its viability for ICF applications can be assessed over the next few years.

The HIFAR program addresses the generation of high-power, high-brightness beams of heavy ions, the understanding of the scaling laws in this novel physics regime, and the validation of new accelerator strategies, to cut costs. Key elements to be addressed include: I) Beam quality limits set by transverse and longitudinal beam physics; 2) Development of induction accelerating modules, and multiple-beam hardware, at affordable costs; 3) Acceleration of multiple beams with current amplification -- both new features in a linac -- without significant dilution of the optical quality of the beams; 4) Final bunching, transpon, and accurate focussing on a small target. 


\section{HIGHLIGH'TS}

D. Keefe

1. We began experiments with the newly-completed MBE-4 apparatus at the beginning of FY88. The early design of a few years ago called for (a) a final kinetic energy of $200 \mathrm{kV}+$ $24 \times 30 \mathrm{kV}=920 \mathrm{kV}$ comesponding to the $200-\mathrm{kV}$ injector and the 24 accelerating gaps, and (b) a current amplification factor (CAF) of 4 to 4.5 , in what was considered an "aggressive" acceleration schedule. The highest kinetic energy observed to date was $950 \mathrm{kV}$, and the highest CAF about 8.0 - both in excess of the original goals. Experinents are beginning now with less extreme acceleration schedules, to address the detailed question of proper control of the bunch ends.

For context, we note that the CAF is made up of two factors, one in velocity $\frac{\mathrm{v}_{\mathrm{f}}}{\mathrm{v}_{\mathrm{i}}}$, and the other in pulse length $\frac{\ell_{f}}{\ell_{i}}$ Typical values for a driver are:

Velocity factor $\approx 50$; Length factor $\approx 4$; (for a CAF of about 200 );

whereas, for the above-quoted results from MBE-4:

Velocity factor $=2.1 ;$ Length factor $=3.8$.

Since HIFAR is constrained to conduct scaled experiments at energies orders of magnitude less than a driver we cannot, therefore, realistically attain a large velocity factor.

Nonetheless, in terms of the length factor we observe that MBE-4 can provide a stringent test of longitudinal manipulation in the relatively shor length of the experiment.

With such a large current amplification, the final beam-current pulse shape in MBE-4 is dominated by rise-time effects (pulsers typically $200 \mathrm{~ns}$, gap-transit 300-150 ns) which, for a driver with a much longer pulse $(10-20 \mu \mathrm{sec})$, would be very much less significant. For this reason and for improved operational stability, detailed studies of the beam dynamics will be made at an energy and CAF both about $20 \%$ below the highest values.

Long-term stability of operation, i.e., shot-to-shot reproducibility, is inmortant for effective data-gathering. Again for context, we note that in the Single Beam Transport 
Experiment (SBTE) data was acquired at various z-locations for the beam position and anglc coordinates $\left[x_{0}(z), x_{0}^{\prime}(z), y_{0}(z), y_{0}^{\prime}(z)\right]$, and for the density-in-phase-space distributions $\left[f_{x}(z), f_{y}(z)\right]$. Data-gathering in MBE-4 is more complicated by far because of the higher dimensionality of the measurements; for example, each of the above quantities must also be measured as a function of $t$, the time-coordinate within the pulse. In addition, the energy $E\left(z_{f}, t\right)$, and energy spread $E\left(z_{f}, t\right)$, nust be measured although the beam is only accessible for precise measurement at the end of the accelerator, $\mathrm{z}_{\Gamma}$. (The usually rather good agreement with the SLID macro-particle code allows the inference of $E(z, t)$ at other locations). Finally, of course, four beams rather than the one in SBTE, need to be diagnosed. An extensive program to improve and extend the diagnostic capabilities is a major part of the MBE-4 program. We note that in ILSE, with 16 beams, the complexity will become further increased.

2. The carbon arc source, with a fast on-gate, developed by S. Humphries (UNM) has satisfactory emission current-density, as reported in the previous half-year report (LBL-24519). Extensive measurements of emittance have now been made and the timeaveraged emittance (over 1000 shots per scan) is larger by a factor of four than hoped for. The raw data, however, show considerable fluctuations from shot to shot so that the actual emittance (if it could be measured in a single shot) is less, and a true value cannot be stated until the problem of irreproducibility has been solved. Changes in the geometry, materials and circuitry are being pursued in a systematic semi-empirical manner to improve reproducibility and lifetime. Since we wish to use the SBTE (where the source is mounted at present) for fundamental beam physics measurements, a sepurate $200-\mathrm{kV}$ test-stand is being prepared for future tests of the source.

3. Upon receipt of the parts of the 2-MV injector from LANL in September 1987, we assembled the components in the $750 \mathrm{kV}$ configuration first tested at LANL. After upgrading some of the components to improve reliability, successful testing (50) shots) was achieved. Because of Congressional action (continuing resolution), at delay occurred in ondering the 
inductive corona rings and longer suppon beams needed for the re-configuration to an LCgenerator. Electrical punch-through of the molded plastic tray supports emerged as a recurring problem and we have begun to replace them with lucite trays. Preparations are underway for proceeding to a $750-\mathrm{kV}$ LC generator test in the latter half of FY88 before proceeding to the finally intended $2-\mathrm{M}^{\mathrm{V}} \mathrm{LC}$ configuration.

The architecture of the control system has been mapped out. Development of components is being done in close conjunction with the Controls Group for the Advanced Light Source (ALS) with mutual design and cost advantages.

4. The conceptual engineering design of ILSE began to come up to full speed toward the end of this reporting period with the addition of a strong team of mechanical and electrical engineers. We are fortunate to have, in addition, the participation (on a part-time basis) of a number of engineers from the Beam Research Group at LLNL, who have had extensive experience in the construction of electron induction linacs.

There have now been several generations of the physics design for ILSE. Each of the separate sections of ILSE (e.g., electrostatic-focussed, combiner, magnetic focussed, bend) taken by itself, has its own preferred set of parameters such as lattice half-period, or undepressed tune, $\sigma_{0}$. In general, these do not match across the interfaces between adjacent sections and the iterations have involved a succession of compromises (usually minor) to make the physics design properly self-consistent.

With the entry of significant engineering expertise into the picture, we recognize that further changes to the design are inevitable. The physics design, by itself, naturally emphasizes a short lattice period, which allows (a) more current to be transported and (b) a higher gradient because of more frequent accelerating gaps (one per half-period). The basic engineering challenge, however, lies in the optimal packaging of the three fundamental subsystems - focus elements, accelerating elements, vacuum system - all of which are in Strong competition with each other for axial space. Taken together, the engineering realities create pressure for longer lattice period and lower volt-seconds per meter, i.e., exactly 
counter to the most-favored physics designs. The challenge is to find the best trade-off among these conflicting requirements.

Two points need emphasis. That the physics and engineering desires are in conflict, on the one hand, and the engineering subsystems compete among themselves, on the other, comes as no surprise, and has been generally recognized for years. The supreme value of the ILSE design process lies in facing up to a realistic self-consistent design for hardware that must perform, and in learning the best course to steer among the conflicts. That process will develop a methodology of compromise invaluable to understanding the design of a full-scale driver. Second, it must be noted that the competition among conflicting requirements culined for ILSE are illustrative of the most difficult design problems in a driver - the lowenergy end, where the fraction of axial space occupied by the lenses is $50 \%$ or more. As one proceeds down the length of a driver, the fraction of length devoted to focussing drops rapidly below $50 \%$ and is typically $10 \%$ or less for the major part of the accelerator, whereupon the conflicts alluded to are greatly alleviated.

5. We report herein on some specific issues for the ILSE conceptual design:

- The physics design is close to being complete but some incompatibilities with the present configuration of the 2-MV injector have been identified; these will dictate some further minor changes.

A new solution for the optics of the beam-combining section has been found in which electric and magnetic elements are used both to bend and to focus the beams. This socalled "combined-function system" has been translated into an enginerring conceptual lay-out.

- There has been progress on the fundamental packaging problem of the engineering subsystems for the magnetic-focussed section.

- The difficult 3-D problem of non-linearities introduced at the ends of the magnetic lenses has been treated with the aim of finding a conductor-winding configuration which nulls in an integral sense - the effects of the most damaging multipole component (dodecapole). 
- A kinematic mounting system devised for the 16-beam electric-focus array can achieve tolerances better than needed in ILSE and looks a promising approach for a driver. The survey reference is provided by a laser beam.

6. The question of the alignment tolerance of the focussing system in a driver has been extended to include the effects of acceleration and changing half-period for a reference case derived from the HIFSA study. For a driver with the urrealistic assumption of no steering corrections whatsoever, a typical tolerance is 0.4 mils transversely. The question of the tolerances in the longitudinal placement of the lenses has been also examined quantitatively; these are much more relaxed than the transverse tolerances and pose no particular engineering problems. 


\section{MBE-4 ACCELERATION}

H. Meuth ind A. Warwick

In the past few months, following the completion of all MBE.4's accelcrator scctions A through $F$ we havr implenzented a conpleze acceleration schedule for the ertire accelerator. We use the SLID code, ${ }^{1}$ starting from measured currents $(-10 \mathrm{~mA})$ and energy profiles $(-200 \mathrm{kcV})$ al box M04. As a first step. we concentrated on a rather vigorous schedule that vtiljzes all the accelcrator modules to their currently available voltage limits. We achieved a fina! peak current in excess of $80 \mathrm{~mA}$ per beam, see Fig. 1 (20 mA/div). as measured at box 30. Simultancously we performed SLID computations that incorporate all the actual acceleration waveforms, taking into account corrections for the transit limes of the bunch through the accelerator gaps. The resulting overall schedule achieved the proposed ${ }^{2}$ final beam energy of $0.9 \mathrm{keV}$ at the beam bunch center (Fig. 2). Aside from details in curren: and energy pulse waveforms we find that the computed and measured waveforms at all diagnostic boxes agree generally weil. An energy calibration factor requirad for the code was based on time-of-flight drift measurements on the current bunch through the entire MBE-4 device thereby providing a substantially higher calibration accuracy than that for the carlicr results with a shorter devi,e. 3 Similarly, the gwactor was determined by the head and tail erosion of the drifting beam.

Af can be seen from Fig. 1 we have nol yet been able to produce a square-type current waveform at box 30 . The waveform becomes increasingly trapezoidal, until at box 30 . the Hat lop has vanished altogether. Figure 3 shows this effect alteady taking place by the time the team has reached box 10. In comparison to the pulse shape at box M04, the rise and fall times of the pulse have doubled while the bunch widuh has halved by pulse compression with a resulting current amplification of 1.8. The reasons for lack of comianinent of the bunch head and tail are: (a) the rise times of the acceleration pulser waveforms are limited to at least $200 \mathrm{~ns}$. With a final pulse width of about 600 ns (at the base), there is therefore not much lefit for a flat top. Secondly (b), ther is a crucial limilation due of the SLID code which attempss to faithfully replicate at every gap. the waveform of the preceding gup. no matter how much the latter deviates from the desired squate shapc, thereby accumulating errors in the beam pulse shape. Future work will tackle a slightly less vigorous schedule to eliminate pulser trigger failure and crosstalk. and will also include "manual" tuning improvement that starts from a SLID-based tune.

\section{Refirences}

1. C.H. Kim and L. Smilh, Particle Accelerators 18, 101 (1985).
2. R.T. Avery, Program Plan for the MBEad Multiple Beam Experiment, PUB-5142, LBL-19592 (1985).

3. A.h. Warwick e1, al., Proc. of the Conf, on Heaty lon Incrtial Fusion, Washington. D.C.. 1986.

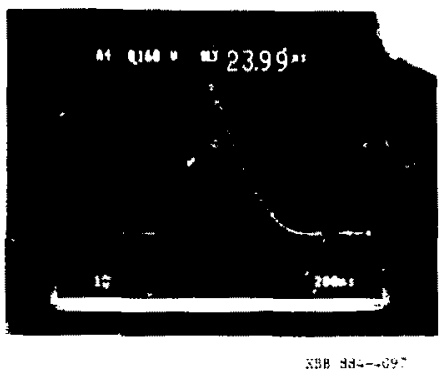

Fig. 1

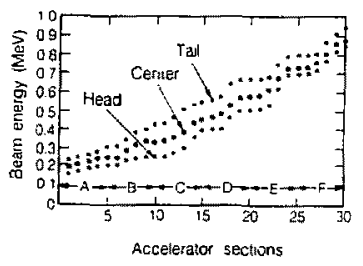

XEL 50ل

Fig. 2

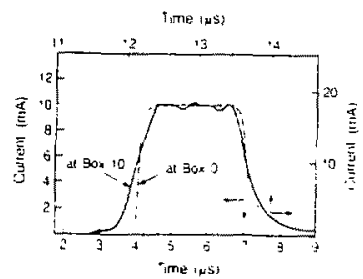

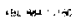

Fig. 3 


\section{MODIFICATIONS TO MBE-4}

\section{A. Warwick, H. Meuth. D. Yanecek and W. B. Ghiorso}

The construction of MBE-4 was completed in Scptember. FY87. However, modifications continue to be made as difficulties arise or improvements are needed.

Replacement parts for the four hot surface ionixalion sources are continually required. With slow thermal eycling and no accidents, a se: of filaments lasts typically two to thuee weeks,

Stepping motors have beer added to all inserlable diagnostics, allowing each device to be remotely controlled by the diagnostic computer keyboard. Measurements of the current waveforms along this length of the aceclerator are now more casily made.

Al the end of the accelerttor the beam energy varies with lime through the bunch. We have measured the approximate shape of this energy waveform in the past and now require improved encrgy and time resolution to observe any rapid חuctuations of the kinctic energy as a function of time. To this end new detectors bave been built with improved frequency response. Use of a $\times 50$ amplifier with $200 \Omega$ input impedance, mounted at the delector, gives a time response of approximately $10 \mathrm{~ns}$. The energy resolution is then deternined by the collimation, limited by the smallest usable signal. Collimating with $0.004^{\prime \prime}$ stits at two locations $18^{\prime \prime}$ apart upsucam of the analyzer deflecting plates and using a detector with sense wires separated by 0.04 " gives an encrgy resolution better than $0.2 \%$.

Inprovements have been made in the sensitivity of the transverse emittarce measurements. The width of the all slits was reduced to 0.004 " and a new fabrication technique "was adopted whereby slits for all four beams are electro-formed in a single metal sheet. This ensures precise relative alignment between the four beams. The optical techniques for the relative alignment of the ujurtam and downstream slits (see figure) have been perfected. Signals from this equipment are now quitt low and the signal-to-noise ratio is improved by integralion on a $1 \mathrm{k} \Omega$ resistor vlose to the detector. A line driver is then used to uransfer the signal through $50 \Omega$ cable to the oscilloscope. The time resolution is approximately $150 \mathrm{~ns}$ which is adequate for resolving emitunce variations through the $2 \mu$ s bunch duration.

Emittance measuruments with increased sensitivity revealed a halo around the beam caused by the non-lincarities of the focusing fields at the edge of the aperture. The particles at the edges of the beams experience these non-linear forces during the large envelope excursions in the second and thitel quadrupules during matching. Elliplical collimalors, corresponding to the measired bedm size, were introduced in diagnostic box $\mathrm{Ml}$ to remove some of the halo (abuut one percent of the cotal bean inlensity). These greatly reduced the effect of the halo on the measured r.m.s. Emitlance. Whe Find the r.m.s. emittance thet includes $95 \%$ of the intensity al the beginning of the acelerator to be:

$$
\pi \varepsilon_{n}=4 \pi B \gamma \varepsilon_{\mathrm{r}, \mathrm{m} . \mathrm{s} \cdot}=1.5 \pm 0.3 \times 10^{-7} \pi \mathrm{m} \mathrm{rad}
$$

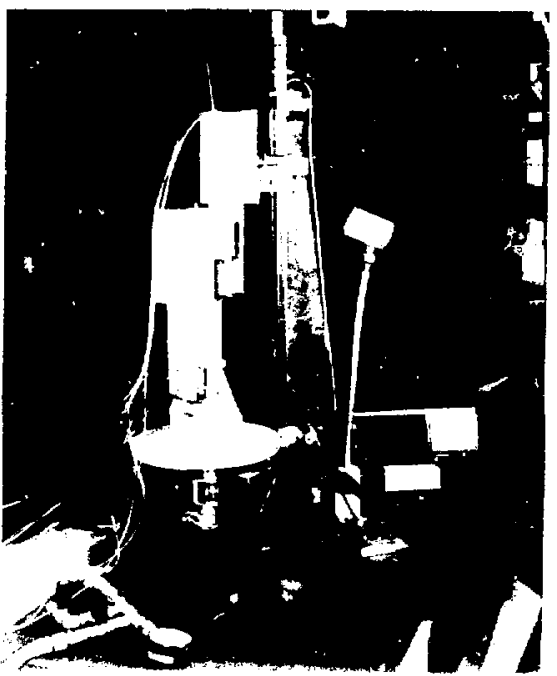

CBS $881-618$

Figure 1. Equijment deceloped for the precise alignment of the emiltane mbasuring system. 


\section{CARBON ARC SOURCE DEVELOPMENT}

\section{H. L. Rutkowski}

The two main activities for the last periud have been the attempt to get source performance to be uniform and reproducible, and, to measure the source emiltance. The quality of tne emittance measurements depends on the reproducibility of the source because we measure emittance with two sliss. getting one data point on each shot.

Initially, we thought that the most important thing was to get a good trigger plasma in order to get a good main discluarge which creates a more uniform plasma for extraction. Simultaneously we want the source to have long life. Consequently, we installed an alumina uigger issulator and tried to tune the source by sliding the trigger to different distances from the main arc. Our indices of performance were: temporal conformity between the ion-plasma signal from the source with the are discharge pulse shape and case of ion shut off with the plasma switch. We never obtained good shut off with this trigger and we had a high misfire rate.

Emittance plots contained holes at random points where one would expect to sec beam. Before changing the source, we chucked tine extractable cument density with a gridless deep Faraday cup that was scaled from a standard LBL design. The results are shown in Fig.1. Clearly, the extraction of adequate current density is not a problem for the are source, but getting adequate reproducibility is.

The next step was to try Lise type of trigger that I. Brown uses in the MEVVA sources. This method uses a solid carbon cathode rod with a ceramic insulating ring around it at the arc discharge end and a stainless steel electrode ring around the ceramic. The front surfaces of all three components are flush. Thus, the trigger plasmu does not need to migrate inlo the main are gap from the cathode interior. The emittance scans sgain showed holes in the data. Before changing the source we installed a shallow grifless cup designed by $S$. Humphries and again veri.jed that the gun was emitting the expected Child-Lanjmuir c:trent density, up to $28 \mathrm{~mA} / \mathrm{cm}^{2}$. Finally, we verified that the secondary electon amplification, which we were using in the slit-cup to get usable emittance signals, was not the source of the data variations. A line driver was placed in the system and the slit eup biased normally. Hoth slits werc left on eenter and six shots were taken. The signals were non-rejroducitle shot to shot.

Finally, we have replaced the single cylindrical cathode with three carton rods equally sipaeed so that the outer diameter of the array is the same as the outer diameter of the original single cathode. The cathode intemal trigger is replaced by a two-wise surface flashover on alumina inside die three-rod array. The concept was to have multiple ares and smooth out the statistical fluctuatiens of any one arc. Other than these changes, the source renlained the same. To remove all current density saturation during extraction the arc current has to be $300 \mathrm{~A}$. The emittance data still showed holes though the source secmed to be behaving better it the beginning, indicating that aging might be nccurring during the scan. Latet, a recent scan at higher plasma switch voltage showed fewer holes even though the source had not been rebuilt. The switch voltage was $160 \mathrm{~V}$, which is in a region where switch breakdown has normally occurred in the past. This effecl is still being investigated.

In order to fecilitate the testing of different versions of the are, and to allow the SBTE to retum to its original mission, an ion source test stand is being assembled which will have $200 \mathrm{kV}$ capability and considerable diagnustic flexibility.

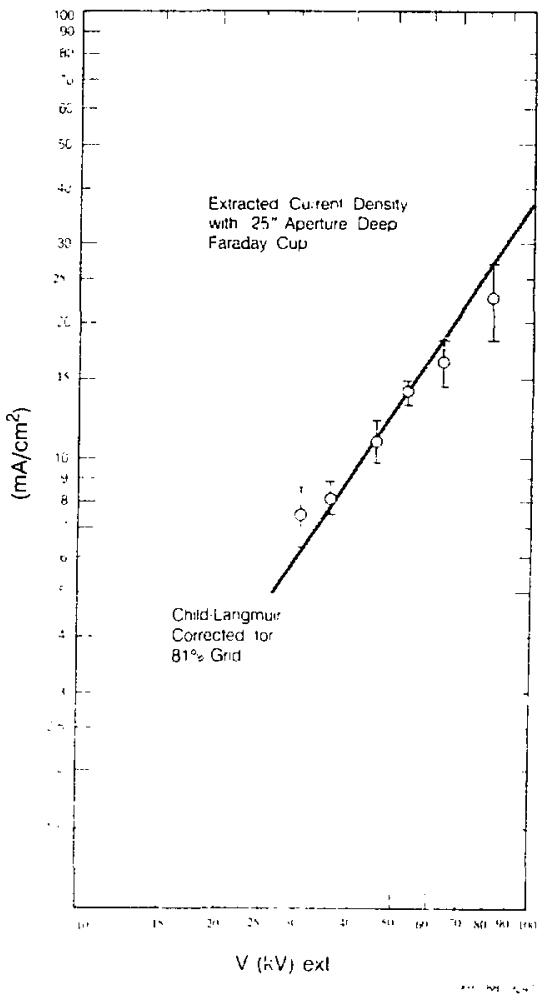

Fig. 1 


\title{
2-MV INJECTOR
}

\author{
H. L. Rutkowski
}

After the parts for the injector Marx generator were obtained from LANL, and the experimental facilities had been prepared, we reassembied the system in the same configuration that was used at LANL. The first test firing occurred on Dec. 22, 1987. The insulating gas used was 65 psig. of $\mathrm{N}_{2}$ and the load resistor was the $\mathrm{CuSO}_{4}$ dummy load which was sent from LANL. The syslem expezienced some conditioning breskdowns but eventually fired successfully several times at $90 \mathrm{kV}$ charge voltage ( $100 \mathrm{kV}$ is full charge). At [ull charge, however, there was breakdown and upon opening the pressure vessel, it was discovered that most of the liquid was gone from the dummy load and that several trigzer resistors and charging resistors had been destroyed. In the next test, the dummy load was a pair of Ion Physics Corp. solid composition resistors in series, each rated for $500 \mathrm{kV}$ and each with $4 \mathrm{k} \Omega$ resistance. After researching the available information on the energy and power handling capabilities of the trigger resistors, they were changed from singlets to triplets to increase their chances of surviving the $200 \mathrm{kV}$ impulse load that they experience when the Marx lires. The insulating gas was 65 psig. $30 \% \mathrm{SF}_{6}-70 \% \mathrm{~N}_{2}$. The system worked at full voltage for a $\mathrm{few}$ shots and then broke down. The failure mode was breakdown of the trigger capacitors which were installed by LANL to reduce jitter. These capacitors were underrated for the impulse voltage that they experience when the Marx fires.

At this point, attention shifted to the question of how to ensure trigger component reliability while still fitting cumponents into the limited space available. Because there was no $\mathrm{SF}_{6}$ recovery system available, all subsequent tests were carricd out in 65 psig of $d r y^{4}$ air, the logic being that the most robust configuration should be found that would place the least reliance on the insulating gas. Several trigger resistor combinations were tried, but adding more resistors to increase rcliability caused congestion of components which resulted in Hashover problems between adjacent components. The trigger capacitors were no longer a problem after one capacitor was added to each set. The n,aximum number of shots obtained at full voltage in any configuration without incident was 50 .

In the original design, there are two parallel trigger lines that run down the entire system along the upper comers of the trays. One set of trigger components is connected across two stages, at fling, resulting in a $200 \mathrm{kV}$ pulse across it. Also. they are located very close to the corona rings which, in the new inductively graded design, will be replaced with inductive corona rings. The design was chaiaged to place the trigger components on the interior of the trays away from the corona rings, and to change to a single trigger string with each component set connected across only one slage thus cutting the voltage it experiences in half. Two trays were assembied in this new configuration and were used to replace the upper two trays of the system. The lower two trays were left unchanged. The first tests started at the beginning of March. Problems were encountered due to penetrations through the Maxwell trays and to surface tracking. A quick test revealed that the surface hold-off of the tray material was different on each sioe of the tray and in general inferior to the surface hold-off of lucite by almost a faclor of 2 . Lucite barriers have been constructed on the two trays with the new circuit and the system is currently being tested. An $\mathrm{SF}_{6}$ recovery system is being set up and subsequent tests will use $\mathbf{S F}_{6}$. Another aspeel of the design being pursued is the possibility of triggering only the first few stages of the Marx thus eliminating mueh trigger circuitry together with its additional weight and its additional failure potential.

Other activities are underway towards the completion of the 2-MV generator. After being held up foi budgetury reasons, the order for the inductive corona rings was placed in January, All of the lucite coil forms and 12 of the spinnings are finished and being shipped to LBL. Once live rings are finished, which requires coil winding and some high veltage testing at LBL, they wili be installed in the five tray Marx that we now have to study the final circuit ennliguration and to test the induclively loaded Marx concept on a small scale.

The longer support beams necded for the inductively graded Marx are on order as are the pressure vessel extensions. Both are expected in the first half of May due to surprisingly long delivery times.

The capacitors chosen for the 2-MV system arc undergoing life tests under pressure. So far, one $100 \mathrm{kV}$ capacitor has been tested in a pressure vessel filled with 65 psig $\mathrm{SF}_{6}$, using a critically damped test circuit that duplicates the design waveform. The capacitor has 300,000 shots on it and is still running. The capacitor has experienced some pressure cycling because from time to time other components in the test circuit have failed, requiring the pressure vessel to be opened for repair work.

Design of the column electrodes for the 500-mA-per-bean $\mathrm{C}^{+}$tesis has continued. There is now a layout drawing of the high voltage connections to the new shorter column. The high voltage design with no heam appears 5 . isfactory. Of course, there is always risk of breakduwn with beam present especially in a column which pushes the known tcchnology limits. The problem of matching the beam into ILSE is also being investigated. The reentrant geometry of the column, the size and divergence of the beam make this a chitlenging problem. 


\title{
2-MV INJECTOR CONTROL SYSTEM
}

\author{
Don Brodrik
}

A system to implement remote control of the 2-MV source and support electronics is described. This system must be consistent with bolh immediate local control and eventual integration within an overall IISE control system concept.

Control philosophy will follow that of a highly distributed microprocessor-based architecture. This will track and make use of the work done by the ALS Control group. 1,2 Initially the souree and the Marx generator will be controlled. Later, status infomiation for the vacuum and interlock systems will be provided. Further, there will be a requirement for controi of the 2-MV water load and shell cooling. The control system will provide a means for accessing machine components so that their values may be set and/or mortitored remoiely. Machine status will be displayed and so[tware will be provided for archival saving and retricval of machine parameters. The control system will be a distributed system based on many high performance microcomputers of the Intel family ( $80 \mathrm{C} 186,80286$, and 80386) operaling in parallel. By using a compatible family of processors the interface among the various parts of the system will be greatly simplified. Programs will be written mostly in high-level languages (Basic, Fortran, PLM, C, and Pascal). The processor used in the main part of the control system will be an Intel 80386. General systern architecture is as shown in Fig. 1. This microprocessor has the hardware-supported capability to run multiple operating systems simultancously [MS/PC DOS, OS 2 UNTX (XENIX). or RMX, a real-time operating system]. The basic features that will br as incorpurated into the design are:

Local debugging capability.

High level progranming languages.

Homogeneous procussor architecture throughout the system.

- Ease of maintenance and repair.

- Use of work stations.

Data driven suftware capability.

Built in help functions.

\section{LC Intelligent Locol Controller}

The ILC is shown schematically in Fig. 2. The unil presently exists on a $6 \mathrm{U}$ Eurocard form and will later be made available in a $\mathbf{3 U}$ form. Chips are CMOS; power consumption is 10 watts. The cpu is a $80 \mathrm{C} 186$ running at $16 \mathrm{Mhz}$. The memory will be 64Kbytes of battery-backed RAM. A serial communications cpu will exchange data and/or programs with a remote external Collecior Micro Module. The bont resources will include a math coprocessor, a $S B X$ bus interface (to match other buscs e.g. GPIB or RS 232), and four channels of ADC, four channels of DAC and finally 24 1/O cisunels.

\section{Arc. Source}

We plan light pipes, one for a real time trigger the other for transmitud and received data. The total length of this cable is approximately 15 feet. The time available between shots for data extraction and processing is 10 seconds. If ono assumes a lMbaud light-pipe rate, data extraction should be possible within 50 milliscconds.

\section{Shell_LC Summary}

The shell source would constitute at a minimum one ILC (Intelligent Local Controller, see Fig, 2) inputoutput work station. This would exist on a 485 multidrop bus. The liber optics would just be an extension of the 485 bus. Gradually a number of ILC's (source. water, vacuum, water load) could be connecled to this bus. Initially, they would communicate with and be controlled by an IBM AT via an expansion card with an SBX bus capability. Formulation of diagnostic and or cmittance stations would follow a similat philosophy. System implementation would then be by sections, yet with each section able tn stand on its own, with the IBM AT and the software that was developed for that section serving as a potential work station/debugging tool. Sections would then have the capahitity of being integrated via their serial links to a central CMM (collector memory module) as described in Fig. 1.

\section{Rererences}

1. Conceptual Design Report - July 1986 for the 1-2 Gev Synchrotron Radiation Source Pab - $5172 \mathrm{Rev}$.

2. The Uranium Beams Project [Lancaster et.al., 1979: Magyary et al.. 1981a; Magyary et al., 1981b|). 


\section{PROGRESS TOWARD A SELF-CONSISTENT PHYSICS DESIGN FOR ILSE}

\section{T.J. Fessenden}

During this past period the physics design of the Induction Linac Systems Experiment (ILSE) was further refined. Calculations 1 of the cumulative effects of misalignments indicated that a maximum specification of 0.1 $\mathrm{mm}$ on the placement of the focusing electrodes in the electrostatic quadrupole focusing arrays and the injector electrudes was required to assure that the beam offsets at the combiner would be no more than one millimeter. Enginecring indicated that this could be accomplished with the dynamic support system described in this report. This support system requires that upproximately $20 \mathrm{~cm}$ per half lattice period be devoted to the support elements which restricts the space available for the induction accelerators. To accommodate the need for more axial space and to provide as much axial space as possible for the accelerator units, a strawman physics design ${ }^{2}$ was developed with half-latlice periods near the maximum determined by the beamlet current at each point in the accelerator.

The physics design was developed with the aid of the code INDEX developed by Charles Kim. In the design each cighth half-lattice period contains no aceelerstor so 25 to provide pumping and diagnostic access. To limit the length of the accelerator and combining section to approximately 30 meters, an average accelesator gradient of $375 \mathrm{kV} / \mathrm{m}$ was chosen. This gradient will be difficult to achicve. Table 1 contains a summary of some of the pargneters of the design.

Table 1: Some parameters of the Physics Design

$\begin{array}{llllll}\text { \# beams } & \text { periods } & \begin{array}{c}\text { energy } \\ \text { (MV) }\end{array} & \begin{array}{c}\text { current } \\ (\text { A) }\end{array} & \begin{array}{l}\text { period } \\ (\mathrm{m})\end{array} & \begin{array}{l}\text { quad bure } \\ (\mathrm{mm})\end{array} \\ 16 & 1-23 & 2-4 \mathrm{MV} & 8-11 \mathrm{~A} & 0.4 \mathrm{~m} & 27.0 \mathrm{~mm} \\ 16.4 & 24.29 & 4 & 11 & 0.5 & 27-55 \\ 4 & 30-44 & 4-6.5 & 11.17 & 0.5 & 55 \\ 4 & 45-62 & 6.5-10 & 17-20 & 0.6 & 55\end{array}$

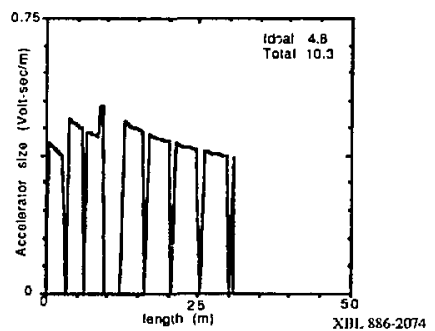

Fig. 1 Size of Accelerating . nits versus length

Figure 1 shows the size of the accelcrator units along the length of the accelerator as calculated by INDEX. The unit of size is volt-sceonds/meter. The physical dimensions of the unils will be set by the properties of magnetic material used in the accelerator units. If the waveforms requested by INDEX could be perfectly synthesized, 4.8 volt-seconds of magnetic material are required for the entire accelerator. If allowance is made for the rise and fall of the waveforms as suggested by Fallens ${ }^{3}$, a lotal of 10.3 volt-seconds is required.

Figure 2 shows INDEX calculatians of the boam tail. center, and head along the accelerator. The relative velocity tilt $(\Delta B / B$; at the combiner is $24 \%$ and at the end of the accelerator is $9.6 \%$. The current growth along the accelerator is shown in fig. 3 . The dots represent calculations of the size of the $\mathrm{K}-\mathrm{V}$ beam that would occupy one half the aperture radius at the corresponding beamlet current ard energy.

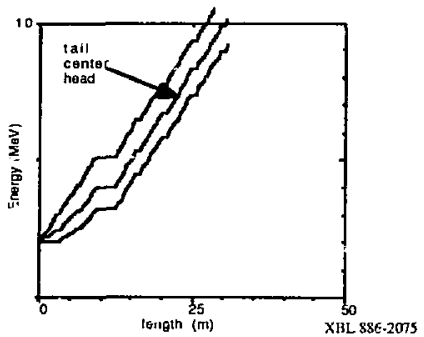

Fig. 2 Energy of the beam along the acceleraior

The integration of this physics strawman design with the 2-MV injector and further study of the beam combiner have revealed several conflicts. At present parameters it appears impossible to match the circular diverging beans froin the injector to an electrostatic quadrupolt transport at the scparations between beams in the injector design. The beamto-beam separation must be increased or the beamlet size and therefore current decreased to find a match. The shortest lattice period of $40 \mathrm{~cm}$ is still too short for a satisfactory resolution of the conflict berween the alignment system and the accelerator core. Becitse of the beam-to-bcan spacing downstream of the combine imposed hy the injector, there is not enough space for the niagnetic quads and aperture necessary to transport the design beamlet current.

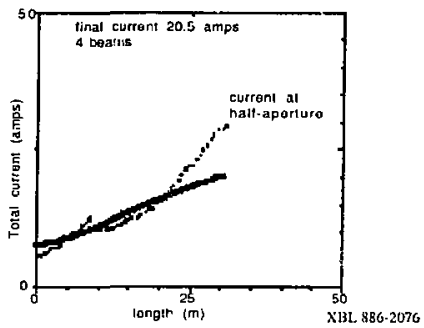

Fig. 3 Tolal acceltrator current versus length

The miltiple-beam, space-charge-limied natus of ion induction linacs for heavy ion fusion imposes many constraints and conflicts in the design of the accelerator. It is clear that additional physies compromises will be needed to duvelop an enginecred conseptual design of ILSE.

\section{References}

1. L. Smith, HIFAR Nole 182, Feb. 1, 1988

2. T. Fessenden, HIFAR Note 180, Jan 14, 1988

3. A. Faltens, HIFAR Note 179. Decomber 11, 1987 


\section{E. Lee and M. Culderon ${ }^{+}$}

The design of a beam combiner for ILSE has recently incorporated combined function clements. That is. clectrodes and nignels simultancously focus and bend the sixteen acceleraced beams as they are maneuvered into the desired four beam clusters of the stonehenge configuration. The primary impetus for combined function is to avoid a serivus loss of ions by scrape-off in the finul bend, which appears to be intrinsic in the usual separated-function designs. Thus, at least the final bend and quadrupole must be combined. It is found that combined function has several additional good features which can be exploited through the whole combiner. These are (1) fewer beam line elements (by a factor of (wo), (2) lower fields (also by a factor of two), (3) larger ratio of element length to bore, which reduees some abertations. These three qualities are important in ILSE because the very shore hat period ( $2=40 \mathrm{~cm}$ ) places a premium on available space. The potential disadvantage in combined function is the complexily of shapes and positions of the electrodes and riagnets. There may also be an increased level of aberrations, which would incrense the effective bean emitlance. These multurs are being studied at present.

The specific layout of beim-line elements which has been tentatively selected is a first-order double achromat containing thire full focal periods. Element lengliss are all $24 \mathrm{~cm}$ (60\% of the hall period), including the final half strength quadrupole/bend. This achromatic lattice layout, shown in Fig. 1 , consists of five electric combined-function elements in the crotrance and middle areas and two magnetic. combined ?unctions elements at the exit. The choice of magnetic elements is made to eliminate possible electrical breakdown. Six of the elements shown in the figure are symmetrically localed about the center-line of the $40 \mathrm{~cm}$, half-period locations and a seventh has been offsel a small anount to provide a properly matched beam at exit.

A guadrant of the typical electric combined-function (C-F) element shown in Fig. 2 is an array of tubular clectrodes which produce a guadrupole field. The center electrode in each quadrant is shaped ${ }^{2}$ to give posituve (inwad) bending of the beans. At the next downstream location, negative bending occurs when the potentials are reversed.

To provide small-displacement corrections to the beam trajectories ( $\pm 2 \mathrm{~mm}$ ), the element located in the middle of the combinet has been divided into quarters to permit small voltuge adjustments. 2 This electrode feature derives from a requirement to form the stonehenge beam pattern within \pm 1 $\mathrm{mm}$ at the exit.

In the last iwo lacations of the combinet the focusing and bending functions are provided by a pulsed magnetic element of "birdcage" beometry. 3.4 These elements focus and bend the beams by current distrituted ficlds formed by the conductors around the beams. A laminated iron structure encloses the "birdcage" magnet structures to shicld each magnet from the olhers 3,4 and to return the flux. To accurately locate each of the conductors, placement grooves are mathined in the iron and a then, 300 -saries stainless stet sheet as welded oves the insulated conductors to capture and prevent movement due to the small magnetic forces. Small vent holes irom the grooves obviate trapped volumes.
While heat loads from the power puise (a few nsec) are calculated to be low, cooling car casily be provided to the iron structure if it should later seen appropriate.

At this point in the design we envision all the focusing bending clements supporled from a stable, kinematically functioning platform that is isolated from the vacuum tank envelope. The alignment and adjustments of the elements would be made relative to the support platform. Alignment of the entire combiner artay and support platform assembly to the machine center line would ie by external electro. mechanical sensors penetrating the tark wall. ${ }^{5}$

At present the enginecring effors is directed to identifying the type and placement of the clements in the combiner design. This woik has guided the development of a general design in the form of a layout. In a rext phase, detailed designs for individual components can begin.

\section{Belerences}

1. E. Lec, 3/3/88, Archromatic Beam Combiner with Combined Function Elements. HIFAR Note-191.

2. A. Faltens 3/11/88, Oral Communication.

3. D. Judd. 8/87. HIFAR Note-162.

4. A. Faltens, $8 / 14 / 88$, HIFAR Nole-163

S. R. Fulton and D. Vanecek, 3!22/88, Oral Communication.

+Lawrence Livermore Laboratory.

Schematlc of Boam Conbiner

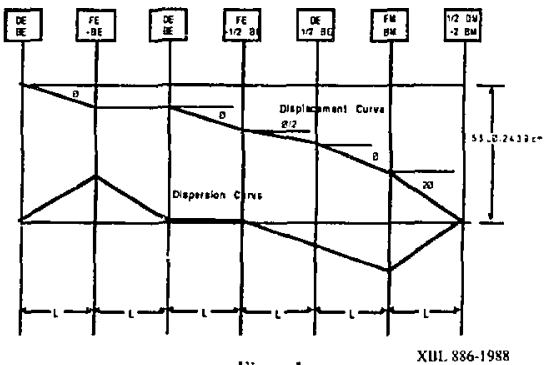

Fig. 1

XI1. $886-1988$

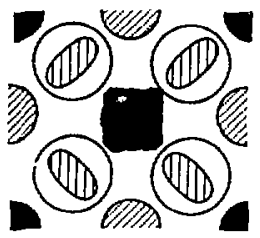

XI1L. 886-20า7

Fig. 2 Combined Function Elcelrostatic Array. 


\title{
PACKAGING STUDY FOR THE ILSE MAGNETIC FOCUS INDUCTION CELLS
}

\author{
D. Bubp, ${ }^{+}$D. Ravenscroft, ${ }^{+}$L. Reginato, ${ }^{+}$A. Faltens, and D. Vanecek
}

A detailed packaging study for the ILSE magnetie for'ss induction cells was initiated in March. The emphasis to date has been to integrate the magnetic focus quodrupoles with the induction cell design. The basis was the physics strawman contained in reference 1 with a $50 \mathrm{~cm}$ half-period and an interbearn seperation or pitsh of $14 \mathrm{~cm}$.

As the initial packaging study a cell block was aid out. The configuration consists of seven cells with both acceleration and focus capability, and an eighth, dumuy cell. The dummy cell has the magnetic foeus capability, but no acceleration potential. The dummy cell provides the vacuum pumping station, and the space for beam diagnostics. The initial packaging study yielded the following conclusions:

Packaging of the metglas corcs neccssitated large diameter ( 1.5 meter) geometries. However, standard widths of nonferrous materials range from approximately $1.2 \mathrm{~m}$ to $1.5 \mathrm{~m}$ staximum;

The pulsed quadrupole arrays were badly squeczed, and would be very difficult to fabricate;

The vacuum tubulation for the proposed eight-cell block configuration was restrictive. Alnough detailed vacuum calculations werc not done, the clastomer seals chosen would provide an appreciable gas load for the available iscuum concuctance. Elastomer seals were chosen to minimize the radial build factor for each of the four (merged) beanpipes;

A monolithic ceramic insulator at the induction cell .cceierater gap was favored over four individual ceramic irsulators for ease of assambly and lessenco expense of machining for the adjacent hardware;

The utilization of a gascous dielectric in the core area was favored over a liquid for high voltage insulation. Liquid dielectrics were considered (Freon, uansformer oil, MIPB. clc.) but rejected, since the high vacuum system would be badly contaminated with the liquid dielectric in the event of a ceramic insulator failure;

Both 2" and 4" metglas core windings were considered in the initial study. Although the $2^{\prime \prime}$ cores result in a

Figure 1 A quadrant of each pulsed quadrupole design concept is shown above. The arrays as pictured show a cut in the midsection of the quadrupole perper,dicular to the ion beam. longer axial build, conventional thyratron/SCR swilched pulses can be used. The 4" metglas. core designs reguire spark gap switched pulsed-power sources or sicp-up transformers coupled to thyratrons.

In late March, beam transport calculations were shown to overfill the individual beam tubes were considered in the initial study.

A second phase of the packaging study was immediately initiated for magnetic quadrupoles with interbeam spacings of 18 and $20 \mathrm{~cm}$. The pulsed quads for the larger spacings require increased power. but cooling of the quads is casicr. Also, enhanced vacuum pumping is a gain for the larger designs. Figure I shows design concepts for the pulsed quadrupole windings. Figure iA depicts the initial concept of using solid square conductor with indirect cooling via axial atir flow. Figure iE shows a monolithic aluminum mandrel for the four individual windings in each quad. This design concept utilizes low conducting water cooling channels as shown and relies on tangential heat conduction to the cooling chanels. The potted assembly must stand off an estimated $10 \mathrm{kV}$ to ground (coils in series clectrically, hydraulic channels in parallel). The cooling channel conneclions must exit through the laminated iron core to minimize the radial build factor. Figure 1C incerporates a prinled circuit array approach. Multiple printed circuits would have to be utilizcd to achicve the conductor cross section for the necessary power dissipated. Figure 1D utilizes a water cooled capillary conductor. Preliminary calculations indicate that for the postulated rep. rate of $1 / 10 \mathrm{~Hz}$. laminar flow cooling will be adequale.
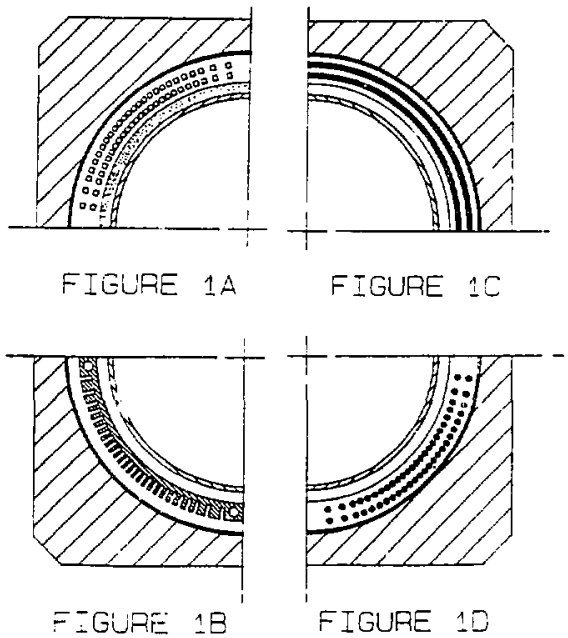

'T. Fessenden, "A Straw Physics Design for ILSE," HIFAR Note-180, Jan. 1986.

${ }^{+}$Lawrence Livermore National Laboratory. 


\section{FIELD CHARACTERISTICS OF ILSE MAGNETIC QUADRUPOLE LENSES}

\section{J. Laslett and V. O. Brady}

The frcusing elements to be employed in the LLSE device downstream from the combiner region will be pulsed roomtemperature quadrupole lenses, with the current windings placed in a configuration that could be adapted to a supercondueting D.C. design for a driver. The main windings in such a design are longitudinally placed in two layers on the surface of a circular cylinder, in an approximatcly $\cos 2 \theta$ pattern, and a sharp 90-degree transition to the end windings serves to economize on the overall length of the assembly (see Fig. 1). The detailed angular locations and lengths of the individual turns have been so computed as to suppress the dodecapole component of the field in the integral sense (i.c., when integrated over a quarter lattice period), as has becn considered a desirable procedure in the design of similar eomponents for the projected Superconducting Super Collider.

This quadrupole design has been described by $V .0$. Brady in HIFAR Note-147 (corrected copy, dtd. 5 June 1987) and it will provide a cleas aperture of about $5.5 \mathrm{~cm}$ radius for an elument intended to form a part of a transport latliee of half period as short as 40.0 or $50.0 \mathrm{~cm}$. Although past experience presents no basis for supposing that this rather large aperture atuo could be detrimental to the single-particle dynamics in such a lattice, it can be informative to examine the effect of the associated field notlinearitics upon individual-particle motion and prudent to undertake simulation computations relating to the collective stability of a bearn traversing this lattice. To this purpose we have made computations designed to indicate the type of magnetic field (including the nature of the end fields) to be expected from such a quadrupole design, to organize the results in a manner convenient for subsequent simulation computations, and in exanine the characteristics of individual-particle motion (with and without space charge) in such a lattice.

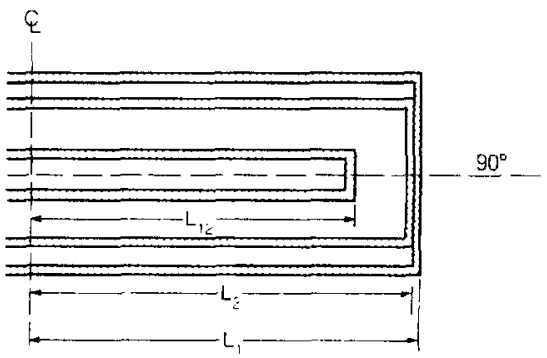

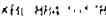

Fig. 1 Developed view of upper windings for one half of current-dominated quadrupole. The hall lengths of the individual turns increase steadily from $\mathrm{L}_{12}=6.6$ cm to $\mathrm{L}_{1}=8.8 \mathrm{~cm}$.
The magnetic field components of the proposed quadrupole element have been evaluated (ignoring the presence of possible (erromagnetic shiclding) litrough use of the Ampere-law program MAFCO. The resulis have been analyzed (after adjustments made in recognition of the periodicity of the assembled lattice) to provide coefficients for expressions that specify the field components in terms of power series in i (for example through ${ }^{7}$ for the transverse components, and through $r^{6}$ for $B_{Z}$ ), circular functions of arguments 20 and 60 . and a periodic trigonometric development in $z$ (or. alcematively, at definite specified periodic locations in $\%$.. for use in numerical integration in connection with subsequent multi-particle simulations).

For orientation computations concerning individualparticle dynamics, such representations of the applied-ficld components can be supplemented, when desired, by a C.W linear defocusing ficld as an approximate representution of the action of space charge to effect a depression of iune. The results of such computations have provided guidance coneerning the number of terms th it may be suitably used to describe in a consistent way the character of the applied fields from the quadrupole latice (c.b.. using 10-term or 12-term trigonometric developments and power series extending through $r^{7}$ ), and indicate values of eurrent strength and intensity parameters that will result in the attainment of desired small-amplitude ture values $\left\langle\sigma_{0}\right.$ and $\sigma$ ). Similar computations also provide an interesting indication of the variation of such rine values with oseillation amplitude (sec Fig. 2) and also serve to corroborate our expectation that individual-particle motion wil! become unstable under typical operation conditions only for motion extending well outside the amplitude permitied by the physical aperture of the quadrupole lenses.

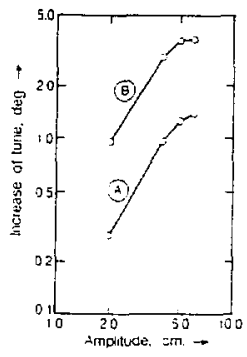

IFL 3041019

Fig. 2 Dependence of tune upжn amplitude: A. Space chirge absent, small-aplitude $\sigma_{0}=80^{\circ}$ : B. With space. charge tune depression, small-amplitude $\sigma=16^{\circ}$. The departure of these log log plots from linearity is chicfly ascribable to the dodecapole compontint of the ficld. 


\title{
CONCEPTUAL DESIGN FOR THE ILSE ELECTROSTATIC FOCUSING ACCELERATOR SUPPORT AND ALIGNMENT
}

\author{
L. J. Hansen and R. L. Fulion
}

The mechanical design of the electrostatic-focusing accelerator section to meet the ILSE physics design ${ }^{l}$ has been under study with the objective of developing a new concept for alignment of the focusing electrodes. The present fourbeam accelerator, MBE-4, ${ }^{2}$ is built in a "conventional" manner in that all its focusing electrodes are mounted and located with respect to the vacuum walls, which are in turn machined accurately and then assembled with the accelerating insulator and aligned to the accuracy required for the electrode assemblies. This method of construction for ILSE has several s.rawbacks: 1) it is not kinematic - yacuum loads, temperature variations and building motions can affect the electrode aray positions, 2) it has more, and larger. components require precision machining tolerances, 3) its tolerance stackup leads to larger positional enors, and 4) there is no provision for realignment of the individual electrode arrays after installation.

The approach taken in the present ILSE design is to provide separate support for the electrode arrays, vacuum wall and induclion cores, since they each have very different positional tolerance requirements. A schematic of the dynamic support concept is prescnted in Fig. 1. The focusing electrode urrays, installed in array rings inside the vacuum wall, are suppor'cd by constant force tension members incorporating positioning devices that can either manually or autoınatically adjust the amays' position and alignment. Most of the 0.004 in positional tolerance ${ }^{1}$ will be used within the electrode array itself, making the requirements on the support

\section{Dynamic Support Concept tor Focus Arrays \\ Achieves $0.1 \mathrm{~mm}$ Alignment Tolerance}

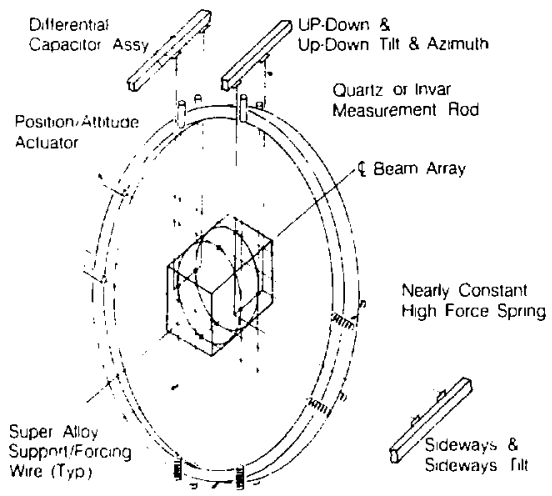

Electrostatic

Assy Support Ring

Figure I. Support and alignment concept for ILSE. and alignment system much more stringent than on previous systems. The anray rings are in turn supported by tension members through bellows feedthrus in the vacuum wall to the precision positioning actuators on the support structure. The system of support tension members and actuators provides control of horizontal and vertical transverse position, along with pitch, roll and yaw rotation, of the array ring and electrode assemblies. Roll is the most eritical rotation, translating into a transverse positional error for beams not on the axis. Position along the accelerator axis, which is not as critical, is controlled by having the tension members angled slightly along the 2 -axis, providing adequate stiffness and thus natural frequency of the urray.

Measurement of the electrode array position is done by using offset rods of some stable, low coefficient of thermal expansion, material to aceurately transfer the electrode position to the alignment system. Figure 2 shows conceptually a proposed scheme for a global-sectional-local alignment system. This allows the determination of transyerse position and all three rotations of each electrode array.

Induction pulse cor's for each accelerating gap will be mounted to an independent support structure, thus isolating the core weight from eithar the focus electrode arrays or the vacuum envelope. The corcs will be insulated with a gaseous insulator, most likely sulphur hexafluoride, and connected electrically with the accelerating gap and insulator through a flexible connecting wall that can allow limited relative snotion between the components. Further work on this aspect of the design will be done during the next half year.

\section{References}

1. T.J. Fessenden, "Progress Toward...." this report.

2. R.T. Avcry. "Program Plan for the MBE-4 Multiple Beam Experiment," LBL-19592, Feb. 1985.

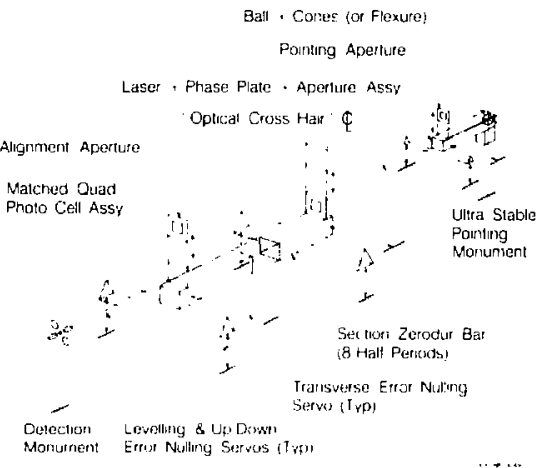

Figure 2. Conceptual schematic of a method for establishing a global/sectional alignment coordinate system. 


\section{TRANSVERSE MIS-ALIGNMENTS IN A DRIVER}

L. Smith

Transverse errors in quadrupole position stimulate a transverse coherent oscillation of the beam, the amplitude of which tends to increase as the beam encounters more and more mis-aligned lenses. In conventional accelerators this effect can be corrected quite well by observing the displacement of the beam and applying a transverse kick at an appropriate place to bring it back on axis. In an induction linac driver, this process is complicated by the fact that the head and tail of the bunch have substantially different velocities - as mueh as $31 \%$ at the law energy end - at a given quadrupole location. The induced amplitudes are different from head to tall but, more importanl, the phase advances per focusing period are different and coherent oscillations get out of phase with each other. At the point where it is desired to make a correction, one would obseric, not a rigidly displaced bunch, but an object looking like a cork-screw during time of passage. The ooservation and correction would both have to be timedependent; an experiment addressing this problem is being pl tunned fer MBE-4.

In view of the fact that this style of correction has never been done and the fact that toward the end of a driver the time scale approaches $100 \mathrm{~ns}$ and the required kicks would increase with incrensing kinetic energy. it seemed useful to calculate the consequences of abandoning any atempt at correction. To this end the formalism developed in H1FAN note 251 (July, 1981) was applied to a sample driver supplied by E. Lec. This driver, for $4 \mathrm{MJ}$ at charge state 3 . is a distillation of the most economically appealing cases produced by the cosi program, LIACEP.

The result is shown in the accompanying figure, which

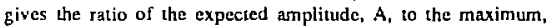
$\Delta$, of an assumed uniform distribution of emors as a function of accumulated megavolts along the accelcrator (kinetic cnergy in $\mathrm{MeV}$ equals $3 \mathrm{MV}$ ). In distance, the $60 \mathrm{MV}$ point is at $\sim 400$ melers and the $3000 \mathrm{MV}$ point at $~ 3.6$ kilometers. There are about 1500 focusing periods in total. In a uniform channel with no acceleration, $A / \Delta-\sqrt{N}$, whirh is clearly not the case in the figurc. There are two reasons for the difference. With acceleration, the amplitudes are damped as the square root of the velocily. In the example used, acceleration begins slowly in favor of bunching the beam as rapidly as possible and the amplitude increasts roughly as $\sqrt{N}$. Then acceleration builds up rapidly to a nomina? maximum rate of $1 \mathrm{MV} / \mathrm{m}$ and in this portion the damping of the early contributions dominates the new contributions out to about $100 \mathrm{MV}$. Thereafter the lattice parameters are also changing, turther upsetting the $\sqrt{\mathrm{N}}$ rule. At the end, $2 \sqrt{\mathrm{N}}=$ $2 \sqrt{1500} \sim 80$, which agrees with the figure, but the agreenent must be a coincidence for the particular model.

Consideration of the final focusing system indicates $\mathrm{A} \approx$ $1 \mathrm{~mm}$. That calls for a 10 micron tolerance, which might not be entirely absurd considering the current rapid advances in alignment techniques. If such a precision were possible, the tolerance on the low energy end could be relaxed considerably because the acceleration damping greally reduces the contribution of early erors to the amplitude at the end of the aceclerator. In the meantime, an experiment on correcting orbits is certainly important.

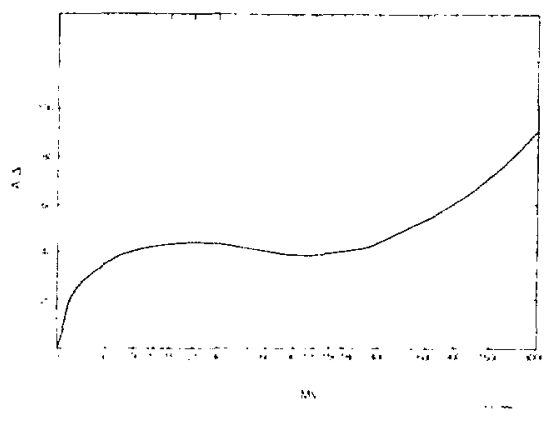




\section{TOLERANCE ON LONGITUDINAL POSITION OF QUADRUPOLES}

L. Smith

\section{INTRODUCTION}

It has been assumed, rightly enough, that the tolerance on longitudinal placement of quadrupoles in a transport line is much less restrictive than the tolerance on transverse position. On the other hand, the procedure for longitudinal positioning might be inherently less precise than for transverse positioning and a quantitative estimate of the effect of longitudinal errors is needed. The qualitative effects are quite different; a transverse displacement induces a transverse coherent oscillation for which the motion of the centroid may be treated as single-particle motion, while a longitudinal displacement induces an envelope oscillation with the two Iransverse degrees of freedom coupled through the strong space charge force.

\section{PROCEDURE}

To good approximation for the HIFAR parameter range, the einitance term in the envelope equations may be neglected, leaving only the quadrupole and space charge terms to be considered. Also, the calcuiation is considerably simplified by tetting the quadrupoles as $\delta$-functions in the longitudinal directions, an approximation which does not affect the results significantly. The procedure is to consider a matched beant governed by the non-linear (due to the space charge term) cnvelope equations encountering a lens which is at the wrong longitudinal position and to calculate to first order in the displacement the resulting deviations in radij and slopes from the matched values. Then, using the linearized envelope equations, the contributions of each error are added linearly to obtain a final envelope oscillation amplitude. Finally, a statistical average is taken over the distribution of errors and a tolerance set by requiring that the oscillation amplitude be reasonably small.

The propagation of the individual errors is complicated by the fact that both transverse degrees of freedom ate involved. Mathematicelly that means that the eigen-vectors and eigen-frequencies of a $4 \times 4$ transfer matrix representing the linearized envelope equations must be obtained and used to propagate the disturbance. Fortunately, this calculation, for the $\delta$-function quads assumed, is not insurmountable.

\section{RESULTS}

The result of this procedure is:

$$
\left(\frac{\Delta a}{a}\right)_{m} \sim 2 \sqrt{\frac{2}{3}} \sqrt{N} \sin \frac{\sigma_{o}}{2} \frac{\Delta_{m}}{L},
$$

where $\frac{\Delta \mathrm{a}}{\mathrm{a}}$ is the fractional amplitude of oscillation, $N$ is the number of periods, $L$ is the period half-length and $\Delta_{m}$ is the maximum of an assumed uniform distribution of errors between $\pm \Delta_{\mathrm{m}}$. As an example for the electrostatic portion of ILSE, taking $\left(\frac{\Delta a}{a}\right)=S \%, \sigma_{0}=60^{\circ}, N=12$ and $L=40 \mathrm{~cm}$, $\Delta_{m}-1 / 4$ inch. This is certainly much more forgiving than the specified ${ }^{1}$ transverse tolerance of several mils, but as the construction of ILSE is presently conceived a specification of $\sim 0.1$ inches for $\Delta_{\mathrm{m}}$ wotild have caused problems.

\section{Referance}

1. L. Smith, "Electrostatic Quadrupole Misalignments in ILSE," HIFAR Note 182. Feb. 1, 1988. 


\section{PUBLICATIONS AND INTERNAL NOTES}

HIFAN-379

LBL-24272

Keefe

D. Keefe

"Induction Linac Drivers for Commercial Heavy-Ion Beam

Fusion," presented at the The Third Inertial Confinement Fusion Systems and Applications Colloquium, Madison, Wisconsin, November 9-11,1987, LBL-24272, HIFAN-379.

HIFAN-380

LBL-24519

Keefe

HIFAN-381

Warwick

A.I. Warwick,

"Range-Energy Relation for Au lons, E/A < $150 \mathrm{MeV}$," Physical Review A

October 15, 1987

HIFAN-382

LBL-24840

Lee

E.P. Lee,

"Heavy Ion Accelerator Driver for Commercial Inertial Confinement Fusion (ICF)

Power," abstract submitted to the Spring Meeting of the American Physical Society, Baltimore, Maryland, April 18-21, 1988 (1/29/88).

HIFAN-383

Celata

C.M. Celata

"Some Thoughts on Beam Combining in ILSE," February 12, 1988.

HIFAN-386

Lee

E.P. Lee

"Cancellation of the Centrifugal Space Charge Force," Proceedings of the Wakefield Workshop held at Lawrence Berkeley Laboratory, Aug. 1987; LBID-1376, HIFAN-386.

HIFAN-387

LBL-24842

Fessenden

T. Fessenden,

"Physics Design of the Induction Linac Systems Experiment," Abstract submitted to the Spring Meeting of the American Physical Society, Baltimore, Maryland, April 18-21, 1988 (1/29/88). 
HIFAN-388

LBL-25047

Lee

E.P. Lee,

"Heavy Ion Induction Linac Drivers for Inertial Confinement Fusion," Abstract submitted to the 8th ANS Topical Meeting in Salt Lake City, October 9-13, 1988 $(3 / 28 / 88)$. 


\section{HIFAR NOTES (Internal and Informal)}

HIFAR NOTE-171

Meuth

H. Meuth and W. Ghiorso,

"A Small Energy Analyzer for MBE-4," October 1987.

HIFAR NOTE-172

Meuth

H. Meuth,

"Cs + Injector Modeling with the EGUN Code," October 1987.

HIFAR NOTE-173

Smith

L. Smith,

"Representation of Fields in Short Lenses or Dipoles," October 1987.

HIFAR NOTE 174

Warwick

T. Warwick,

"Linear Envelope Calculations for MBE-4," October 23, 1987.

HIFAR NOTE-175

Brady

V. Brady,

"Coil Misplacement Studies for ILSE," October 27, 1987.

HIFAR-NOTE- 176

Smith

L. Smith,

"Recent HIFAR Notes Relating to ILSE Designs," November 5, 1987.

HIFAR NOTE-177

Lee

E.P. Lee,

"ILSE $180^{\circ}$ Bend," Presented to HIFAR Group October 29, 1987. Preliminary Survey (11/87).

HIFAR Note-178

Faltens

A. Faltens,

"Voltage Rise and Fall Times." December 11, 1987.

HIFAR Note-179

Faltens

A. Faltens,

"Lambda," January 6, 1988. 
HIFAR NOTE-180

Fessenden

T. Fessenden,

"A Straw Physics Design For ILSE," Viewgraphs presented

to the HIFAR Group January 14, 1988.

HIFAR NOTE-181

Smith

L. Smith,

"Emittance", February 1, 1988.

HIFAR NOTE-182

Smith

L. Smith,

"Electrostatic Quadrupole Misalignments in ILSE", February 1, 1988.

HIFAR i IOTE-183

Celata

C.M. Celata,

"Matching from a Transverse Beam-Combiner into the Downstream Lattice," February 4, 1988.

HIFAR NOTE-184

Hovingh

J. Hovingh,

"LIACEP Versions - Update," February 9, 1988.

HIFAR NOTE-185

Warwick

T. Warwick,

"Transverse Emittance Measurement Techniques for

MBE-4," February 18, 1988.

HIFAR NOTE-186

Faltens

A. Faltens and B. Tiffany

"LANL Marx Tank Pumpdown," February 24, 1988.

HIFAR NOTE-187

Meyer

E. Meyer,

"Suggestions on Fabrication of Inductor Cornna Rings with Input from Dave

Vanecek and Ralph Hipple," February 25, 1988.

HIFAR NOTE-188

Brady

V. Brady

"Single Particle Orbits in the Magnetic Field of the ILSE Current-Dominated

Quadrupole.," February 25, 1988.

HIFAR NOTE-189

Brodzik

D. Brodzik,

"Fjber Optics for the 2MV Source," March 7, 1988. 
HIFAR NOTE-190

Fessenden

T. Fessenden,

"Progress on the ILSE Conceptual Engineering Design," March 3, 1988.

HIFAR NOTE-191

Lee

E.P. Lee,

"Achromatic Beam Combiner with Combined Function

Elements," March 14, 1988. 
Denis Keefe

Donald A. Brodzik

Warren Chupp

Robert D. Edwards

Andris Faltens

Thomas J. Fessencien

Ron Gervasoni

William B. Ghiorso

David Gough

Wayne Greenway

Ralph Hipple

Cai Houston

Charles H. Kim

David Jerko

John Meneghetti

Hermann Meuth

Harry Meyer

Joseph Perez

Chester D. Pike

Thomas Purtell

James Rice, Jr.

Henry L. Rutkowski

Gerald L. Stoker

Bill Tiffany

David Vanecek

Anthony I. Warwick

Gerald West

John Yeager, Jr.

Lloyd Smith

Victor Brady

Christine Celata

Elon Close

David L. Judd

L. Jackson Laslett

Edward P. Lee
Visiting Participants

LANL

E. Meyer

LLNL

D. Bubp

M. Calderon

J. Heefner

D. Ravenscroft

L. Reginato

$\underline{\text { SLAC }}$

William B. Hermmannsfeldt

UNM

S. Humphries 


\section{HALF-YEAR/YEAR-END REPORT: DISTRIBU'TION LIST}

Allied Chemical Conporation

Carl Smith

Argonne National Lab.

Thomas A. Fields

Ronald Martin

Lniversity of Arizona

R. Morse

Batelle

John Hartman

\section{BMD/ATC/SDC}

Milton Hawie

Brian Strickland

Brookhaven National Laboratory

Mark Barton

E. Courant

C.E.A. Bruyeres-le-Chatel

R. Dei-Cas

\section{CEBAF}

J. Bisognano

D. Douglas

H. Grunder

G. Krafft

C. Leemann
University of Calif. Irvine

Norman Rostoker

Comell University

John Nation

Ravi N. Sudan

DARPA

H. Lee Buchanan

Department of Defense (SDIO)

Richard Gullickson

W. Higgins

\section{Department of Energy}

DP-OIF

Gregory D'Alessio

Sheldon L. Kahalas

R. Shriever

Marshall Sluyter

ER

Ryszard Gajewski (AEP)

Gerry Peters (HENP)

Walter Polansky (AEP)

Robert Rader (OPA)

D. Stevens (BES)

David F. Sutter (HENP)

James Decker, Dir.,

Office of Energy Research 


\section{DOE San Office}

Rudolf Bredderman

Dennis Neely

E.P.R.I.

Robert Scott

Femi National Accelerator Lab.

Frank T. Cole

Fred Mills

Lee Teng

F.O.M. Amsterdam

F. Siebenlist

Fusion Power Associates

Steven Dean

GANIL

P. Lapostolle

GE

John Lucek

GHG Associates

G.H. Gillespie

GSI
R. Bock
D. Boehne
I. Hofmann

University of Illinois

G. Miley
Institute for Nuclear Study

Y. Hirao

KMS Fusion, Inc.

Alex Glass

Kanazawa University

S. Kawaski

Lawrence Berkeley Laboratory

D. Attwood, 80/101

R. Avery, 46/189

K. Berkner, 50/149

D. Brodzik, 46/125

C. Celata, $47 / 112$

W.W. Chupp, 47/112

S. Chattopadhyay, $47 / 112$

T. Elioff, 90/4040

A. Faltens, 47/112

T. Fessenden, 47/112

C. Fong, 47-112

R. Fulton, 90-2148

A. Garren, 90/4040

D. Gough, 47/112

R. Gough, 50/149

K. Hithn, 47-112

E. Hartwig, 47/112

L. Hanson, 90-2148

H. Heckman, 50/245

T. Henderson, 46/161

E. Hoysr, $46 / 187$

R. Johnson, 50A/4119

D. Judd, $47 / 112$

D. Keefe, $47 / 112$

C. Kim, $47 / 112$

M. Krebs, 50A/4112

W. Kunkel, 4/230

G. Lambertson, 47/112

L.J. Laslett, 47/112

E.P. Lee, $47 / 112$

E. Lofgren, 47/112

J. Marx, 46/161

J. Meneghetti, 46/161

H. Meuth, $47 / 112$

S. Mukherjee, 47-112

J. Peter:on, $47 / 112$

C. Pike, $47 / 112$

G. Rosenblatt, 50A/4119 
H. Rutkowski, 47/112

Martin Reiser

A. Sessler, $4 / 230$

D. Shirley, 50A/4133

Derek Tidman

L. Smith, $47 / 112$

C. Taylor, $46 / 161$

W. Thur, 47-112

D. Vanecek, 58/101

D. Vaughan, 50/149

A. Warwick, $47 / 112$

Max Planck Inst. fur Plasma Physik Garching

Amulf Schluter

Maxwell Laboratories

Lawrence Livermore Laboratory

Library

Roger Bangerter, L-477

W. Barletta, L 626

Richard J. Briggs, L-626

John L. Emmett, L-488

Alex Friedman, L-630

Dennis Hewitt, L-472

Darwin Ho, L-477

John Holzrichter, L-481

William Kruer, L-472

William Krupke, L-488

Bruce Langdon, L-472

J. Lindl, L-477

Jim Mark, L- 477

John Nuckolls, L-295

Louis Reginato, L-526

Erik Storm, L-481

D. Prosnitz, L-626

University of Nagaoka

K. Yatsui

National Bureau of Standards

S. Penner

M. Wilson

Naval Research Laboratory

Steven Bodner

T. Coffey

Terry Godlove

Irving Haber

Philip Sprangle

Peter Turchi

Lockheed

John Siambis

Osaka University, Institute of Laser Engineering

Los Alamos National Laboratory

Jhor Bohachevsky

T. Mochizuki

S. Nakai

Richard Cooper

C. Yamanaka

Robert Jameson

Tom McDonald

Earl Meyer

Roger B. Perkins

University of Padova

Richard Stokes

Tai-Sen Wang

A. Pascolini

M. Pusterla

Doug Wilson 
Physics International

Library

Pulse Sciences, Inc.

Ian Smith

Kurt Nielson

Mike Tiefenback

RAFAEL

Joseph Shiloh

Rutherford Laboratory

John D. Lawson

Chris Pryor

Graham Rees

Sindia Laboratories

Everet H. Beckner

Don Cook

Glenn Kuswa

Tom Martin

J.P. VanDevender

K. Prestwich

W.J. Schafer Associates

Wayne Meyer

Michael J. Monsler

SLAC

W. Herrmannsfeldt, Bin 26

B. Richter, Bin 7

Sokal University

Tetsuya Saito

SOREQ Nuclear Research Center

A. Sternlieb
SIJRA

W. Wallenmeyer, President

IITAN Systems, Inc.

K. Billman

G. Yonas

TRW

J. Gordon

¿. Guiragossian

J. Maniscalco

A.W. Maschke

W. Steele

UCSD

K. Brueckner

UCLA

John Dawson

University of Texas at Austin

Toshi Tajima

URA

Edward Knapp

Varian

S.S. Rosenblum

Westinghouse

M. Nahemow

E. W. Sucov 
Uruversity of Wisconsin

G. Kulcinski

G. Moses

R. Peterson

Other

J.E. Leiss 